\title{
A Study on the Application of " Collective Punishment " in the Teaching Mode of Flipped Classroom in Colleges and Universities
}

\author{
Lou Yuechao \\ Huzhou University \\ Huzhou, China \\ sovg@zjhu.edu.cn
}

\begin{abstract}
It is difficult to carry out the formative assessment of the evaluation of the classroom teaching in the course of classroom teaching. The assessment of the students' ability of judging ability and sharing ability is taken as the core, and the "collective punishment " measures are used to reduce the difficulty in the evaluation process. Based on the development of the smart phone App completed the evaluation process data collection and evaluation the results of the treatment, and ultimately construct the current evaluation methods compatible with the flip classroom teaching mode evaluation.
\end{abstract}

Keywords-Colleges and universities; Flipped classroom; Evaluation of way; Ability to share; Ability to judge

\section{INTRODUCTION}

Since the introduction of the Flipped classroom teaching model has been introduced by the majority of educators have been keenly concerned about the various practical experience papers such as spring bamboo shoots trend appeared in various journals at all levels, but the voice of opposition is endless. We are not going to discuss the technical issues such as the development of learning content and the development of the platform. Let's start by discussing the effect of student learning in the Flipped classroom teaching mode. In colleges and universities, in the face of students in the classroom can not guarantee the effect of learning under the premise of learning content will be turned to extracurricular, that students can not get the effect of learning. Therefore, flipped classroom teaching mode to be implemented smoothly, we must first solve the problem of improving students' extracurricular learning effect. We try to implement the "Collective punishment" teaching evaluation in the classroom to protect and encourage students to learn extracurricular effect, so as to make up for the lack of corresponding evaluation mechanism in the country.

\section{The Present Situation OF FLIPPED Classroom}

\section{Teaching Mode and Evaluation Mode}

The study of the teaching mode of flip teaching is a hot topic in the current educational teaching research, but the corresponding teaching evaluation method is obviously in a backward state. In the case of combing the relevant research literature, we find that there are obvious shortcomings in the classroom teaching evaluation in the case of research and practice of teaching mode, and quite a lot of practice is still using the traditional classroom teaching evaluation method. "Researchers in the current domestic translation of the empirical study of the classroom after the analysis of the current stage of the classroom teaching evaluation is mainly divided into the following two categories: First, the quality of student test results or practical work, and second, Teaching students in the subjective learning attitude of the survey in the study of the country to flip the typical case of the classroom, researchers did not specifically designed to flip the classroom teaching evaluation system.[1]"[2]We use the digital journal network to flip the classroom and evaluation as the keyword search for the title, found that focus on teaching methods to flip the classroom teaching evaluation is relatively small, which is typical of $\mathrm{Li}$ Xin's reference engineering education CDIO teaching quality evaluation system To construct the evaluation system of teaching quality of flipped classroom[2]; Wang Yonghua's index system of teaching evaluation of flip classroom[3]; Li Chengyan and so on using fuzzy analytic hierarchy process to construct the evaluation method of flip classroom[4]; He Hongin and other attempts to formative evaluation as a method of evaluation of the flipped classroom[5]; By combing their research, we can find that they are more inclined to discuss the method of reversing the classroom from the theoretical level, while the practical level of thinking is relatively lacking. Even the practice level of research, there are poor evaluation of the operation of the problem. For example, Wang Yonghua's learning evaluation index system has a total of six first-level indicators, 31 third-level indicators; and $\mathrm{Li}$ Xin's CDIO teaching quality evaluation system is to use Delphi method and cluster analysis to determine the index content, but also with the level of analysis Method to determine the weight. For the time being, whether teachers can master these methods, is it time and energy, are they likely to set aside enough time and energy to implement such evaluations, so as to protect the teaching quality of the classroom? Therefore, it is an important basis to construct the simple and easy teaching evaluation method to ensure the practice and popularization of the classroom teaching mode. 


\section{III. "COLLECTIVE PUNISHMENT" EVALUATION WAY}

\section{INTRODUCTION}

"Collective punishment" evaluation method mainly for the college class system teaching form, the core content is the class according to a certain set of rules into a number of learning team. The learning team is a competitive relationship, which helps to motivate students to learn motivation and learning initiative. Team members are cooperative relations between the team to form a community of learning interests, which will help students to learn from each other, cooperative learning and other forms of learning to carry out, in order to achieve the perfect integration of collectivism and individual constructivism. "Collective punishment" evaluation way to stimulate students to learn motivation and learning initiative at the same time, the use of team collective restraint and collective mutual aid to further improve the individual students learning effect.

\section{The EnLightenment of CURREnt Teaching Mode AND}

\section{ITs Evaluation MODE IN COLLEGES AND UNIVERSITIE}

At present in the teaching of colleges and universities, classroom lectures still occupy the dominant position, its evaluation method is still used in the final exam this final sound of the final evaluation of the way. With the social, information and educational environment changes, students access to knowledge and information more and more widely, and students' learning will continue to decline, the current teaching model and its evaluation methods have been unable to adapt to the current teaching of higher education status quo. This adaptation has seriously affected the quality of teaching in colleges and universities, the negative impact of the following three main aspects.

\section{A. The prevalence of student utilitarianism}

Utilitarianism itself does not matter good or bad, but in the current university teaching management system, the prevalence of student utilitarianism brought a lot of behavior contrary to the behavior of learning, such as pre-test assault behavior, test cheating. The prevalence of these acts, seriously dampen the enthusiasm of students usually learning. In addition, the current evaluation method of final examinations can not correctly identify students 'learning ability and knowledge level, and sometimes can only assess the students' short-term memory ability, which is an important reason leading to college students high score low energy phenomenon, but also dampen the students The enthusiasm of learning in peacetime. Therefore, the traditional teaching evaluation gives us the inspiration is to use the formative evaluation to replace the final evaluation, so that the score and the student's actual learning ability to be equal, which is to protect the smooth transfer of classroom teaching mode necessary conditions for the smooth development.

\section{B. Lack of willingness to cooperate among students}

In the current teaching model and evaluation mode, the student individual is a competitive relationship. Competitive sub-benign competition and vicious competition, healthy competition is someone else to study hard, their own more hard to learn, so as to achieve the purpose of winning competition. Vicious competition is the interference of others when learning, others rest their own learning, so as to achieve the purpose of winning competition. The traditional way of evaluation is to encourage students to make healthy competition, but it can not avoid the existence of vicious competition, in some of the current college students learning environment is declining background, the vicious competition has a dominant trend. In addition, according to the study pyramid theory, teamwork learning has higher learning efficiency than individual learning alone. Will be similar to the level of knowledge of students together to form a learning group is the quality of school teaching is superior to the quality of social teaching the most important factor. Therefore, the traditional teaching evaluation to our inspiration is the evaluation must encourage students to teamwork awareness, so as to help to further improve the quality of school teaching.

\section{Students lack of initiative}

First of all, student to reduce the pressure to lead to student learning initiative. After entering the university, students do not have the test, college entrance examination and other school pressure, students take the initiative to learn the will and motivation are inadequate. Second, students lack of awareness of the university curriculum led to lack of student learning initiative. A large part of the university curriculum is a theoretical course, relatively boring, students can not understand its meaning before the need to remember, so the theory is considered by the students is rote course, the theory has become a "sleep class." Finally, students' recognition of university teaching content is not high, resulting in students learning initiative. Seniors will tell the younger brother of the school, the University of the contents of the useless, the community is also widely circulated with the university curriculum and the content of the work is not related to cross-industry employment phenomenon is widespread. These subconsciously affect the initiative of students to learn, resulting in student learning initiative. And flip the classroom teaching mode will be more knowledge of the content of learning to student self-study, students need more learning initiative, therefore, to stimulate students to learn initiative will be the key to protect the implementation of the classroom, and evaluation is to stimulate students learning the main means of initiative.

\section{THE PURPOSE OF TEACHING EVALUATION IN THE FLIPPED}

\section{CLASSROOM}

According to the characteristics of traditional classroom teaching evaluation and the characteristics of flipped classroom teaching mode, we will split the purpose of flipped classroom teaching evaluation into the following four aspects;

\section{A. Improve the quality of teaching}

Flipped classroom teaching mode Compared with the traditional classroom teaching mode, the knowledge content of learning into the extracurricular, in the classroom is to carry out more ability training, so as to achieve the purpose of improving the quality of classroom teaching. And as a way to flip the evaluation of the course, you need from the 
extracurricular learning effect and the ability to train the two aspects of the content of the content evaluation. In terms of class capacity, we think that we should focus on the ability of students to share and judge the ability of these two aspects, through the classroom show that we can examine the level of their ability to share, but also to examine their extracurricular learning effect; we can examine their ability to judge. In the end, our evaluation method achieves the quantitative evaluation of students 'learning effect through the evaluation of students' extracurricular learning effect, classroom sharing ability and classroom evaluation ability, so as to achieve the goal of improving teaching quality.

\section{B. Improve students' willingness to learn}

In the flipped classroom teaching mode, students learn about the content of knowledge in the extracurricular, which requires students in the learning process has enough consciousness and initiative. And stimulate students to learn, we mainly use the following two ways. First, the use of students on the academic performance of the utilitarian needs, through the evaluation of the students' grades and students to study the degree of effort associated. In the evaluation process, students are mainly studying the progress of learning, the greater the degree of progress, the higher the score. Because each student has the possibility of progress through learning, this can avoid the negative effects of the traditional evaluation process, which is conducive to further stimulate students' willingness to learn. Second, the use of the role of supervision between students, through the formation of learning community and community of interests, so that students personal performance and team performance. This way the individual competition of students into a team competition, is conducive to learning to get the full development of competition. In addition, the mutual supervision between members of the team is more conducive to the improvement of students' willingness to learn.

\section{Improve mutual assistance between students}

Whether learning pyramid theory or scenario learning theory, we can find that they are fully affirmed the role of the team in learning. To ensure the learning of the team, we must build a community of learning and community of interests. Learning pyramid theory tells us that team learning helps students to learn more about the content of learning, especially to teach others to make students retention of learning content of $90 \%$.[6] If students are competing, how many students are willing to teach other students, even if there are professors, how many are willing to do it? Therefore, we need to build a student learning community and a community of interests when designing the evaluation system, and to enhance the willingness of students to learn from each other. In addition, the use of learning community and the interests of the internal control of the community, to strengthen the role of supervision between students, so as to protect the initiative of students learning. The mutual learning between students is not only beneficial to the better students to master the knowledge content more solid and more thorough, but also conducive to the poor students to master the knowledge faster, learning and supervision between students is also conducive to the efficiency of learning efficiency. Therefore, the use of evaluation methods to improve student mutual assistance is a win-win measures.

\section{Improve students' ability to judge and share}

By the influence of foreign educational thought, there are too many students' ability to subdivide the students, such as the ability of students to break into critical thinking ability, learning ability, practical ability, practical ability, innovation ability, evaluation ability, comprehensive ability and so on. Too many students' ability to cause the cross between the various competencies, is not conducive to teaching targeted teaching. In the study, we classify students' abilities into two categories: judgment and sharing. In the teaching evaluation of the flip classroom, the evaluation ability of the students 'individual opinions on their own learning results is evaluated, and the evaluation ability is evaluated by the students' ratings.

\section{EVALUATION ALGORITHM AND IMPLEMENTATION}

\section{A. Evaluation algorithm}

Student Individual Final Score $=($ Teacher Rating $*$ Weight A + Student Grade Average Weight *) / (Weight A + Weight B) + Correction Points * Relevance Coefficient C - Deviation

$($ Weight $\mathrm{A}+$ weight $\mathrm{B})+$ correction score $*$ correlation coefficient $\mathrm{C}$ "for the team score, that is, the team members each person obtained the basic points. (The weight of the $\mathrm{A}+$ student score average weight * B) / (weight $\mathrm{A}+$ weight B)

Correction points: According to the original level of the students, given the basic poor students to compensate for the correction points to compensate for the random selection of students between the original levels of the differences brought about by the unfair.

The correlation factor $\mathrm{C}$ : ranges from 0 to 1 . This refers to the degree of relevance of the student's original foundations to the final learning outcomes.

Deviation points: the gap between individual student scoring and teacher scoring, the absolute value of the deviation from the individual students' points.

\section{B. Implementation of evaluation activities}

Evaluation preparation; teachers and students need to install the rating software on the phone and complete the user's registration, the teacher in the software to add the appropriate course, and the software automatically assign the course number to inform the students, students according to the teacher to provide the course number to find and join the course The You must first determine your group when you join a course. On the grouping, we can arbitrarily group students, such as by school number, by dormitory, free combination, etc., but the ideal state of the grouping is heterogeneous grouping, each level of student level contains all levels, which is more conducive to students to carry out teaching activities. Students can choose the appropriate learning content according to their own characteristics, each student needs to prepare themselves in the class will be displayed in the classroom content.

Evaluation process; After class students sign in with scoring software, the students sign the teacher after the use of 
software randomly selected each group of students show, draw the range will automatically remove the students did not sign out. The students are finished in the classroom. After the students show, each student (including the students who are shown) and the teachers will score and submit the students who are shown, and the teachers and students will complete the scoring system and process them. A team of team scores and individual scores for each student.

Here are some of the principles to note: students did not sign and did not score students, their personal scores are zero; did not sign the students have no right to score; if there is no time to sign the situation, the team members The obligation to inform the teacher when the sign is confirmed, otherwise the random draw in the extraction of the students, then the student team members of all the scores are zero points.

\section{CONCLUSION}

The teaching mode of the flipped classroom teaching reflects the change of classroom teaching from "teacher as the center" to "student as the center". The evaluation method of the classroom is fully centered on student learning and student development as the center. Thus ensuring the "student as the center" to flip the effective implementation of classroom teaching model, enhance the students' learning efficiency, improve the quality of teaching in the classroom.

\section{REFERENCES}

[1] Wang Yue. An Empirical Study on Flipping Classroom: Comments and a Summary [J]. Journal of Zhengzhou Normal Education, 2014 No. 2: 15-19. [In Chinese]

[2] Li Xin. Study on Teaching Quality Evaluation System of flipped Classroom - Based on CDIO Teaching Model Evaluation Criteria [J]. E-education Research, No. 3, 2015: 96-100. [In Chinese]

[3] Wang Yonghua. Study on the Teaching Evaluation of the Teaching Mode of the Flipped Classroom [J]. Journal of Teaching and Management, Issue 5, 2015:86-88. (in chinese)

[4] Li Chengyan, Gao Jun, Tang Yuanxin, Chen Deyun.Transfer Classroom Teaching Evaluation System Research [J]. Computer Education, 2015 No. 11:100-103. (in chinese)

[5] He Hongjin. Introducing the Flipped Classroom into Formative Assessment [J].Journal of Nanchang College of Education,2015 No.1:74-76. (in chinese)

[6] Chen Xiaofei. Study on the Flipped Classroom Model [D]. Central China Normal University, 2014:22-23. (in chinese) 